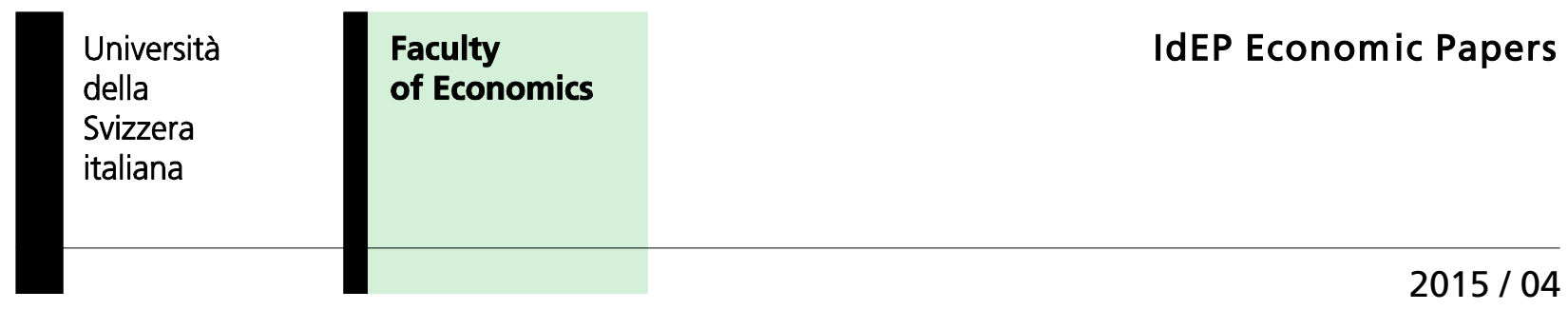

M. Filippini, M. Koller, G. Masiero

Competitive tendering versus performance-based negotiation in Swiss public transport 


\title{
Competitive tendering versus performance-based negotiation in Swiss public transport
}

\author{
M. Filippini * $\quad$ M. Koller ${ }^{\dagger} \quad$ G. Masiero ${ }^{\ddagger}$
}

June 2015

\begin{abstract}
The purpose of this study is to assess differences in the levels of cost efficiency of bus lines operated under competitively tendered contracts and performance-based negotiated contracts. Following the revision of the Swiss railways act in 1996, regional public authorities were given the choice between two different contractual regimes to procure public passenger transport services. We directly compare the impact of competitive tendering and performance-based negotiation by applying a stochastic frontier analysis to the complete dataset of bus lines $(n=630)$ operated by the main Swiss company (Swiss Post) at the same time (in 2009) throughout the country. The overall results show that the differences in the levels of cost efficiency between the two contractual regimes are not significant. Our findings are in line with recent evidence of cost convergence between competitive tendering and performance-based negotiation, and suggest that the practice of using both contractual regimes is challenging for the operators in terms of competitive pressure. The threat of competitive tendering may have a disciplining effect on negotiation since it prevents bus companies from bargaining inadequate rents and inducing asymmetric information advantages.
\end{abstract}

Keywords: public bus contracts, competitive tendering, performancebased negotiation, cost efficiency.

JEL classification: C21, D24, H57, L92.

${ }^{*}$ Institute of Economics (IdEP), Università della Svizzera italiana (USI); Swiss Federal Institute of Technology (ETH), Switzerland.

${ }^{\dagger}$ Swiss Federal Institute of Technology (ETH), Switzerland. Corresponding author. E-mail address: martinkoller@ethz.ch.

${ }^{\ddagger}$ Department of Management, Information and Production Engineering (DIGIP), University of Bergamo, Italy; Institute of Economics (IdEP), Università della Svizzera italiana (USI), Switzerland. 


\section{Introduction}

In recent years, competitive tendering for the provision of public bus services has become a common mean to induce competitive pressure between public or private monopolies in passenger transportation. The idea goes back to Demsetz (1968), who argues that competition for the market is the only way to enhance efficiency when competition in the market is not possible. Many countries applying some form of competitive tendering have been so far successful. Unit costs decreased by about $20 \%$, as compared to those of an unchallenged public monopoly (Preston, 2005). Recent evidence also suggests that firms selected under competitive tendering exhibit higher total factor productivity (Boitani et al., 2013). On the other hand, passengers' satisfaction with trips increased only slightly relative to regions without competitive tendering (Mouwen and Rietveld, 2013). Hence, the impact of competitive tendering is still partially unclear, from both theoretical and empirical perspectives. As suggested by Armstrong and Sappington (2006), many advantages of competitive tendering can be obtained by yardstick competition. The success of competitive tendering depends on numerous factors (e.g. organizational features, playing rules, number of competitors, institutional setting), and careful attention must be paid to the design of crucial aspects (Nash and Wolański, 2010).

The literature is rich of studies on the efficiency of public transportation industries under different contractual regimes (tendering vs. negotiation). However, only few studies try to isolate the effects of changes in the contractual regime from other simultaneous changes or organizational differences. The results are frequently weakened due to an identification problem. To the best of our knowledge, no empirical study has examined differences in the level of cost efficiency of bus lines operated under competitively tendered contracts and bus lines operated under performance-based negotiated contracts. The current study aims at filling this gap in the literature on public transportation services 
by assessing the impact of competitively tendered contracts introduced for bus lines in Switzerland.

The Swiss public passenger transportation industry underwent a fundamental reform with the revision of the Railways act (EBG, 1957) and its legal ordinances in 1996. The reform rearranged the financing schemes and introduced some market mechanisms, similarly to other countries. The main purposes were to enhance productivity, to improve customer satisfaction and service quality, and to keep public transport services affordable. According to the revised act, regional public authorities were given the choice between two different contractual regimes to procure public transport services: to put lines out to tender or to rely on performance-based negotiated contracts.

During the last fifteen years, public authorities in several Swiss regions have exercised their right to put bus lines out to tender. According to Swiss authorities (Bundesversammlung, 2010), this measure is believed to have heightened efficiency and quality levels. However, despite the possibility to put bus lines in a competitive tendering process, the majority of bus lines are procured under performance-based negotiated contracts. The impact of this policy change has not yet been evaluated by means of an econometric methodology. For this purpose, we suggest the use of a total cost frontier approach, which exploits cross-sectional data from more than 500 bus lines operated by the leading bus company in Switzerland (Postbus), that provides bus line services under different contractual regimes after the reform.

As with respect to previous studies, we improve the analysis of the impact of the contractual regime on cost efficiency in many directions. First, we exclude the effects on costs stemming from institutional changes such as the privatization or corporatization process on the contractual regime. This is because we use data on bus lines operated by Postbus in 2009, a division of the public company Swiss Post, which turned into a limited liability company in 2006. According to 
Cambini et al. (2011), most of the efficiency gains on the way from public to private ownership occur in the intermediate stage of corporatization. Furthermore, we compare bus lines that have gone through a competitive tendering process with bus lines that have been procured on performance-based negotiation for the same company and year. Hence, we argue that all aspects not related to the type of contract are held constant. Considering bus lines is also an improvement compared to earlier studies because contract features are based on lines rather than companies. Finally, we use a relatively rich set of controls, which should limit the unobserved heterogeneity (e.g. Farsi et al., 2006; Cullmann et al., 2012).

The paper is organized as follows: Section 2 discusses the main findings of the literature on cost efficiency in public transportation industries related to contracting. Section 3 provides an overview of the reform and the institutional setting. In Section 4, we specify the model and present the econometric approach. Section 5 deals with the data. The estimation results are discussed in Section 6 , together with cost-efficiency measures. We draw some conclusions in Section 7 .

\section{Competitive tendering versus performance-based negotiation in transportation services}

The economic literature is rich of studies on cost efficiency in public transportation industries (railways, bus or ferry lines) related to different contracting regimes (tendering vs. negotiation). However, to the best of our knowledge, only few studies try to isolate the effects of changes in the contractual regime from other simultaneous changes or organizational differences that may affect the outcome of the contractual regime.

A review of successes and failures of competitive tendering worldwide is given 
by Hensher and Wallis (2005). ${ }^{1}$ The authors find evidence of considerable cost savings in the short and medium term. However, they point at four main limitations of previous studies. First, the measurement of savings is inconsistent since countries have different legal backgrounds, and changes in service and quality levels and institutional restructuring are simultaneous with the introduction of the new contractual regime. Second, in most of the cases, only first round effects net of administrative costs are reported. However, costs of retendering may increase due to unreasonable low initial tender prices and a decreasing number of competitors (Wallis et al., 2010; Hensher and Stanley, 2010). Also, competitive tendering may generate administrative costs to operators and regulators (Hensher, 1988; Saussier et al., 2009; Gil and Marion, 2012; Yescombe, 2007). Third, most of the studies focus primarily on cost savings rather than on value for money. This leads to perverse incentives since external benefits are not taken into account, and companies may underestimate the true operating costs to win the race (Armstrong and Sappington, 2006). Finally, Hensher and Wallis object that competitive tendering may be exposed to regulatory capture by powerful providers. As competitive tendering fosters market concentration (Mathisen and Solvoll, 2008; Amaral et al., 2009; 2010; Yvrande-Billon, 2006; Augustin and Walter, 2010), this risk becomes more severe in the long run.

Negotiated contracts or yardstick competition as proposed by Shleifer (1985) can approximate competitive tendering outcomes if they are benchmarked to best practice context-specific costs (Stanley and van de Velde, 2008; YvrandeBillon, 2006). Performance-based negotiation can also avoid some drawbacks of competitive tendering, such as asymmetric information, high transaction costs, lack of trust, and hold-up problems between the incumbent and the public authority. Finally, service quality seem to be much more difficult to specify in

\footnotetext{
${ }^{1}$ See also Alexandersson and Hultén (2006), Smith et al. (2010), Merkert (2010) for competitive tendering in the railway sector; Baird and Wilmsmeier (2011) for tendering of European ferry lines.
} 
competitive tendering contracts (Hensher and Stanley, 2008; Tadelis and Bajari, 2006).

Wallis et al. (2010) underline that the choice between competitive tendering and performance-based negotiation crucially depend on specific circumstances. Among other things, the authors highlight the need for periodic market testing through competitive tendering in order to provide outside information on benchmarking costs as an input to any negotiation strategy. Competitive tendering can then be used when bus companies with performance-based negotiated contracts do not achieve the expected performance or the regulator's commitment power is limited (Armstrong and Sappington, 2007).

A tendency to cost convergence between competitively tendered contracts and performance-based negotiated contracts has been observed in Australia (Wallis et al., 2010). This underlines that the two approaches may be alternative, particularly when monopolists operate in distinct geographic areas (Armstrong and Sappington, 2006).

Roy and Yvrande-Billon (2007) estimate the impact of the contractual regime and the ownership simultaneously on the level of technical efficiency for a panel of French urban transportation networks. Private bus companies under a competitive tendering regime appear to be the more efficient as compared to public bus companies under fixed contracts and cost-plus contracts. Piacenza (2006) draws a similar conclusion for the Italian bus market. However, the effect of the ownership for private bus companies is likely to be bias by the effect of competitive tendering. Other studies compare levels of cost efficiency between public and private bus companies, although the impact of different contractual regimes is not considered. Public bus companies appear to be significantly less efficient than private companies in Japan (Mizutani and Urakami, 2003), whereas weak differences are found in Portugal (Pestana Barros and Peypoch, 2010) and Switzerland (Filippini and Prioni, 2003). 
Cambini et al. (2011) show that corporatization of local public bus companies in Italy may be an effective way to improve efficiency. ${ }^{2}$ On the other hand, as suggested by Filippini and Prioni (1994) and Nieswand and Walter (2010), public bus companies decrease their level of cost efficiency in response to subsidies. The effect of competitive tendering on operating costs and subsidies is examined by Bekken et al. (2006), who focus on the Norwegian bus industry. The authors find that competitive tendering reduces total costs by about $10 \%$. These savings are relatively low compared to other countries, which may be explained by institutional changes and efficiency improvements realized before the introduction of competitive tendering (Dalen and Goméz-Lobo, 2003).

Studies above generally lack in two respects. First, they fail to separate the impact of changes in the institutional form from the impact of changes in the contractual regime. Second, the issue of unobserved heterogeneity is not thoroughly addressed. To the best of our knowledge, no empirical study has examined differences in levels of cost efficiency for bus lines operated under competitively tendered contracts and bus lines operated under performancebased negotiated contracts.

\section{Institutional background and reform}

In Switzerland, cantonal governments are responsible for the organization of regional public bus transportation services. ${ }^{3}$ Hence, cantons define bus lines linking urban transportation networks, railway lines and rural villages that are part of the public transportation network. They stipulate a contract with a passenger transportation company for the supply of transport services on specific bus lines. The bus line network is wide and operated by more than hundred companies. However, the network is dominated by one large bus company,

\footnotetext{
${ }^{2}$ Corporatization refers to the transformation of public enterprises to limited liability public companies.

${ }^{3}$ Switzerland is a confederation made of 26 cantons and about 2500 municipalities.
} 
Postbus Switzerland Ltd. The company operates more than 800 routes on a network of about 10,000 km length, serving more than 100 million passengers, which represents about $60 \%$ market share (LITRA, 2014; Weidmann et al., 2011). These lines include school bus lines, night lines, pure touristic lines, skibus lines, dial-a-bus lines, extra trip lines, and substitution lines for temporarily interrupted railway lines.

Subsequent to the revision of the Swiss railways act in 1996, the public authority was allowed to put lines out to tender in order to impose competitive pressure on passenger transportation companies. ${ }^{4}$ During the last fifteen years, the governments of most Swiss cantons have exercised their right and put some bus lines out to tender. ${ }^{5}$ About $10 \%$ of Postbus lines have gone through a competitive tendering process during the last decade.

Before the reform, passenger transportation companies were compensated for deficits at the end of the operating period, i.e. tariffs were regulated and an automatic ex post coverage of the deficit by the state was in place. According to the revised acts, however, companies are given the opportunity to claim for deficit coverage ex ante, subject to required quality and performance constraints. If the deficit is reasonable according to some benchmarking indicators, then the public authority can negotiate and finally procure the service.

Competitive tendering processes in Switzerland aim at finding a passenger transportation company that operates a bus line, or a bundle of contiguous bus lines, at best value for money, i.e. at the best price-performance ratio. Price cri-

\footnotetext{
${ }^{4}$ The terms competitive contracting, competitive bidding and franchise bidding (or similar versions) are synonyms for competitive tendering used in this study.

${ }^{5}$ The railway act leaves the organization and the design of the competitive tendering process open to the cantonal laws or to the interpretation of cantonal authorities. In order to provide a minimum legal framework, federal authorities set guidelines (BAV, 2003). These guidelines are not normative de jure, but they achieve de facto some normative character since contents and subjects are usually listed as conditions in the competitive tendering documents. However, these guidelines are displaced by legal ordinances in the context of the ongoing reform on the acts concerning railways and public passenger transportations ("Bahnreform II", see Bundesversammlung, 2010). Although the reform does not change the competitive tendering process, it improves legal certainty.
} 
teria include variable and fixed compensation payments, and account for $40 \%$ in the contractual decision. Usually, the level of variable compensation payments is relatively rigid. The remaining $60 \%$ pertains to performance criteria and quality aspects that comprise the following main dimensions: driving training as well as language skills and local knowledge of the employees; security, convenience, maintenance and ecological aspects of the bus fleet; and finally company management, marketing aspects and the overall picture of the applicant. Additional performance criteria, such as environmental, working standards, and willingness to participate in tariff and timetable systems, are mandatory for all applicants. Other important rules apply for the transfer of employees, buses, and other capital equipment in case of operator change. Thereby, the main focus of the law is on employees protection and avoidance of stranded investments. Generally, the winner of the competitive tendering process is provided a license to operate bus lines exclusively for ten years. The company is bound to its offer for the first four years of contract at least. In the following period, changes in external factors, such as the demand, can be asserted.

Despite the possibility to put bus lines in a competitive tendering process, the majority of bus lines are still procured by performance-based negotiated contracts. Performance-based negotiated contracts are renewed annually subject to simple benchmarking indicators, including the most important quality aspects and operating ratios (total costs, revenues per passenger kilometers, revenueto-cost ratio, compensation payments per year and per passenger kilometers, average passengers on a bus, etc.). The renewal of the contract depends on the justification of these ex-ante planned benchmarking indicators. By the end of the year (ex-post), bus companies must give account of benchmarking indicators. 


\section{Model specification and estimation methods}

In order to analyze the impact of the contractual regime on costs and cost efficiency of bus lines, we adopt a cost frontier approach. Within this approach, we apply two empirical strategies. The first empirical strategy is based on the estimation of a stochastic cost frontier model as proposed by Battese and Coelli (1995), where the mean of the cost inefficiency term is a function of a dummy variable indicating the contractual regime. The second strategy is characterized by two stages. In the first stage, we estimate a stochastic cost frontier model as proposed by Aigner et al. (1977). In the second stage, the levels of cost efficiency of the two contractual regimes are compared using a Kruskal-Wallis equality-of-populations test (Kruskal and Wallis, 1952).

We specify a cross-sectional total cost frontier model where total operating cost of a bus line $(C)$ is a function of output and output characteristics, two inputs, and the contractual regime. ${ }^{6}$ Under the assumption of cost-minimizing behavior of bus line managers and convex production technology, we can write the model as follows:

$$
C=f\left(Q, P_{L}, P_{C}, P_{F}, L, S, T, N, d T\right) \text {. }
$$

The output $(Q)$ is measured by passenger kilometers. Equation (1) includes two input price variables: $P_{L}$ is the price of labor, $P_{C}$ is the price of capital, and $P_{F}$ is the fuel price.. To capture possible heterogeneity among bus lines, additional variables have been included. Therefore, $L$ is a load factor and $S$ represents the average travelling speed. Also, $T$ and $N$ stand for the average trip length and network length, respectively. Finally, $d T$ is a dummy variable indicating the contractual regime, i.e. if a bus line is operated under a competitively tendered contract $(d T=1)$ or under a performance-based negotiated contract

\footnotetext{
${ }^{6}$ The use of panel data would be preferred from an econometric point of view. Unfortunately, data at bus line level are available just for one year.
} 
$(d T=0)$. We refer the reader to Section 5 for a more detailed description of variables and data.

For the estimation of the model defined by Equation (1), we specify a translog functional form. This was initially proposed by Christensen et al. (1973) and applied in numerous empirical studies in production economics. The advantages of the translog functional form lies in the flexibility and the straightforward imposition of the linear homogeneity restriction. ${ }^{7,8}$ In the non-homothetic form, the total cost frontier model with translog functional form can be written as: ${ }^{9}$

$$
\begin{aligned}
\ln \left(\frac{C_{i}}{P_{L i}}\right) & =\alpha_{0}+\beta_{Q} \ln Q_{i}+\frac{1}{2} \beta_{Q Q}\left(\ln Q_{i}\right)^{2}+\beta_{P} \ln \frac{P_{C i}}{P_{L i}}+ \\
& +\beta_{P P}\left(\ln \frac{P_{C i}}{P_{L i}}\right)^{2}+\beta_{L} \ln L_{i}+\frac{1}{2} \beta_{L L}\left(\ln L_{i}\right)^{2}+\beta_{S} \ln S_{i}+ \\
& +\frac{1}{2} \beta_{S S}\left(\ln S_{i}\right)^{2}+\beta_{T} \ln T_{i}+\frac{1}{2} \beta_{T T}\left(\ln T_{i}\right)^{2}+\beta_{N} \ln N_{i}+ \\
& +\frac{1}{2} \beta_{N N}\left(\ln N_{i}\right)^{2}+\beta_{Q P} \ln Q_{i} \ln \frac{P_{C i}}{P_{L i}}+\beta_{Q L} \ln Q_{i} \ln L_{i}+ \\
& +\beta_{Q S} \ln Q_{i} \ln S_{i}+\beta_{Q T} \ln Q_{i} \ln T_{i}+\beta_{Q N} \ln Q_{i} \ln N_{i}+ \\
& +\beta_{P L} \ln \frac{P_{C i}}{P_{L i}} \ln L_{i}+\beta_{P S} \ln \frac{P_{C i}}{P_{L i}} \ln S_{i}+\beta_{P T} \ln \frac{P_{C i}}{P_{L i}} \ln T_{i}+ \\
& +\beta_{P N} \ln \frac{P_{C i}}{P_{L i}} \ln N_{i}+\beta_{L S} \ln L_{i} \ln S_{i}+\beta_{L T} \ln L_{i} \ln T_{i}+ \\
& +\beta_{L N} \ln L_{i} \ln N_{i}+\beta_{S T} \ln S_{i} \ln T_{i}+\beta_{S N} \ln S_{i} \ln N_{i}+ \\
& +\beta_{T N} \ln T_{i} \ln N_{i}+\varepsilon_{i},
\end{aligned}
$$

where the subscript $i$ denotes bus lines $i=1,2, \ldots, I$, and $\varepsilon_{i}$ is the composite error term, consisting of the inefficiency $\mu_{i}$ and the random error $\nu_{i}$. We

\footnotetext{
${ }^{7}$ The following restrictions are necessary to guarantee linear homogeneity in inputs: $\sum_{r} \gamma_{P_{r}}=1, \sum_{r=1} \sum_{s=1} \gamma_{P_{C r} P_{C s}}=0$, and $\sum_{r} \lambda_{r m}=0$ for all values $m$. Linear homogeneity implies $C(t \boldsymbol{P}, \boldsymbol{Q})=t C(\boldsymbol{P}, \boldsymbol{Q})$ for any $t>0$. Therefore, one of the inputs, say $P_{C}$, can be arbitrarily chosen and set $t=1 / P_{C}$. Then, one obtains $C(\boldsymbol{P}, \boldsymbol{Q}) / P_{C}=C\left(\boldsymbol{P} / P_{C}, \boldsymbol{Q}\right)$.

${ }^{8}$ Following Jehle and Reny (2001), a cost function conforms to neoclassical microeconomic theory if it is $(a)$ non-negative and non-decreasing in input prices and output, $(b)$ linearly homogeneous, concave and continuous in input prices.

${ }^{9} \mathrm{~A}$ cost function is non-homothetic if input prices depend on output levels, hence if input prices and output levels are not separable. In contrast, a homothetic cost function is separable in prices and output: $C(\boldsymbol{P}, \boldsymbol{Q})=h(\boldsymbol{Q}) c(\boldsymbol{P})$. Further properties of the translog functional form are symmetry $\left(\beta_{m n}=\beta_{n m}\right)$ and positivity $\left(\beta_{m} \geq 0\right)$. The translog functional form requires every unit to have strictly positive outputs.
} 
dropped the fuel price $\left(P_{F}\right)$ because this is constant across the country. Since the translog functional form is a second order Taylor-approximation, the values of the explanatory variables must be normalized to the approximation point. For this purpose, we choose the median value of variables. ${ }^{10}$

Our first empirical strategy (Model I) is based on the estimation of a stochastic cost frontier model, where a dummy variable for the contractual regime $(d T)$ allows some heterogeneity in the mean cost efficiency. Hence, the mean of the cost inefficiency $(\mu)$ is distributed as: $\mu_{i} \sim N+\left(\beta_{d T} d T, \sigma_{\mu}^{2}\right)$. This strategy is estimated in one stage.

The second strategy (Model II) is made of two stages. The first stage estimates a stochastic cost frontier model assuming that all bus lines share the same total cost function. The assumption is reasonable since the production technology does not depend on the underlying contract. The question remains as to whether levels of cost efficiency depend on the contractual regime, i.e. whether cost efficiency of competitively tendered and performance-based negotiated bus lines are statistically different. Following Singh and Coelli (2001), this is evaluated in the second stage of the approach by means of the Kruskal-Wallis equality-of-populations test.

The inefficiency $\left(\mu_{i}\right)$ is estimated using the conditional expectation function, $E\left(\mu_{i} \mid \varepsilon_{i}\right)$, as proposed by Jondrow et al. (1982). The level of cost efficiency of bus line $i\left(C E_{i}\right)$ can then be measured by the ratio between the cost frontier and the actual costs as:

$$
C E_{i}=\frac{\ln C_{\text {frontier }}}{\ln C_{i}}=\exp \left(-E\left[\mu \mid \varepsilon_{i}\right]\right)
$$

where $C_{\text {frontier }}$ indicates the costs of an efficient company. Hence, $C E_{i}$ takes values between 0 and 1, 0.8 implying a level of cost efficiency of $80 \%$. Table 2 summarizes the econometric specifications of the two models used in the study.

\footnotetext{
${ }^{10}$ The median value is preferred to the mean value as an approximation point since it is less affected by outliers.
} 


\section{Data}

This study is based on cross-sectional data with information on about 630 bus lines operated by Postbus under the Swiss railways act during 2009. Some of these lines are excluded from the analysis due to missing values in the variables of interest or unclear differentiation between standard bus lines and dial-a-bus and night lines. None of the remaining 568 bus lines is identified as outlier according to Cook's distance (Cook, 1977). All lines are operated year-round and seven days a week. This means that school bus lines, night lines, pure touristic lines, ski-bus lines, dial-a-bus lines, extra trip lines, and substitution lines for temporarily interrupted railway lines are excluded from the data. The data consists almost exclusively of rural bus lines, sometimes connected to suburbs, and occasionally linked to intra-urban public traffic transportation nodes. According to the contractual regime, bus lines are classified in two groups. The majority, namely 522, are operated under performance-based negotiated contracts, whereas 46 are featured with a competitively tendered contract.

Data are relatively homogeneous and include a rich set of explanatory variables. In addition to usual information on input prices, output and load factor, we dispose of average travelling speed, trip length and network length, which account for a good portion of the remaining heterogeneity in the data (see Table ?? for summary statistics). Therefore, the unobserved heterogeneity problem discussed by Farsi et al. (2006) and Cullmann et al. (2012) is expected to be negligible in our empirical exercise.

Total costs $(C)$ include expenditure for buses and infrastructure as well as for labor, fuel and capital depreciation, and are measured in Swiss Francs. Total costs vary by a factor of about fifteen among bus lines. The output $(Q)$ reflects the demand and is measured by passenger kilometers, used also in similar studies. ${ }^{11}$ Other authors use supply-related output measures such as seat

\footnotetext{
${ }^{11}$ See, for instance, Windle (1988), Deb and Filippini (2011), Bhattacharyya et al. (1995),
} 
or bus kilometers. ${ }^{12}$ De Borger and Kerstens (2008) note that both supply and demand related output measures are relevant. However, the distinction is important when measuring the output of companies operating less frequented bus lines. Generally, a load factor can be applied to control for the mismatch between consumption and production. However, demand remains an important cost driver of bus cleaning and operational asset depreciation, among others. Therefore, we use a demand-related output measure. Also, we argue that production should be adapted to real demand unless reserve capacity is desired by public authorities to guarantee a certain quality level, even in the case of exceptionally high demand in the short-term. Otherwise, inadequate choices of transportation would not be identified as cost inefficiency. Even worse, the most efficient bus companies would be those operating big empty buses (Roy and Yvrande-Billon, 2007). Certainly, intra-day excess capacity arises because of fluctuating demand caused by commuters (peak load). To replace buses several times a day would be inefficient. This constraint is considered by the input price variable for capital and a load factor.

Two different input prices, defined as expenditures per factor unit, are included in the model. The input price of labor $\left(P_{L}\right)$ is defined by the labor expenses per full-time equivalent. In our sample, labor expenses account for about half of total costs. The input price of capital $\left(P_{C}\right)$ is a residual price approximated by the non-labor expenses per bus kilometer, following Friedlaender and Wang Chiang (1983). ${ }^{13}$ Non-labor expenses consist mainly of costs related

and Jha and Singh (2001). Similarly, the number of passenger trips is used in an earlier study by Berechman (1987).

${ }^{12}$ For seat kilometers, see Farsi et al. (2006), Cambini et al. (2011), Walter (2010, 2011). For bus kilometers, see Wang Chiang and Chen (2005), Ottoz et al. (2009), and Sakai and Shoji (2010).

${ }^{13}$ Bus kilometers are determined by multiplying the number of buses on a given network by the average length of their trips. Consequently, our unit price of capital is the price of moving a bus over one kilometer. Usually buses are discharged after a certain operating distance, as maintenance starts to be too costly. As a result, buses drive similar distances during their life cycle. 
to capital expenditure of buses such as interests, depreciation and maintenance. The capital stock apart from the rolling stock is negligible, and the fuel price is constant through all observations. Hence, the residual price method can plausibly approximate the input price for capital.

Two additional output characteristics are included. Following Windle (1988) and many authors modelling output by passenger kilometers, we use passenger kilometers per seat kilometers as load factor $(L)$. This accounts for scheduled buses with low demand, e.g. intra-day excess capacity or low demand in remote areas. Therefore, the load factor is expected to have a negative impact on total costs. Also, we consider the average trip length $(T)$. The longer the average passenger trip, the lower the costs associated with bus stops. ${ }^{14}$

We add two variables on environmental conditions of bus lines. Similarly to Fraquelli et al. (2004) and Piacenza (2006), we measure the average travelling speed $(S)$ by operative bus kilometers per operative working hours of bus drivers. This is a typical quality indicator predetermined by the schedule, which reflects different local traffic and geographic conditions. From the demand side, the time of transfer affects the choice of transportation modes. From the supply side, traffic and other geographic conditions affect working hours and capital requirements (Gagnepain, 1998). Therefore, total costs are expected to decrease with the average travelling speed. The second variable is the size of the network, measured by the network length $(N)$. This accounts for either the boundaries of the geographic area or the public service obligations determined by the authority. ${ }^{15}$ Likely, the size of the network will increase total costs.

\footnotetext{
${ }^{14}$ Mohring (1972) shows this relationship in an article on scale effects and the dependency of demand, waiting time and frequency.

${ }^{15}$ Several studies use this measure. See, for instance, Cullmann et al. (2012), and Roy and Yvrande-Billon (2007). Other authors argue that the appropriate measure to account for scale effects is the number of stops (e.g. Jara-Díaz et al., 2001).
} 


\section{Results}

The regression results of the two models specified in Equation (2) are presented in Table 3. Preliminary regressions were conducted including the year of the tender, as some of the tenders took place a few years before 2009. The idea was to capture the diminishing effect of the tender over the years due to possible modifications in the length of bus lines, number of bus routes, off-peak supply, or passenger frequency. As suggested by Dalen and Goméz-Lobo (2003), ensuing negotiations may have weakening effects on contracts. Since this effect was not substantiated by the data, we dropped the year of tender in final regressions. Finally, we considered dummy variables to account for other geographical and cultural differences (alpine and linguistic regions) in bus lines. Since most of these differences are already captured by other variables and preliminary results were not robust, we excluded these variables from final regressions.

Generally, the estimated coefficients and the first-order terms show the expected signs and are statistically significant. Furthermore, the coefficients are of similar magnitude in all models. Since variables are in natural logarithms, the estimated coefficients can be interpreted as cost elasticities at the approximation point. For example, a rise in average travelling speed $(S)$ by one percent reduces total costs by about 0.34 percent in both models.

The coefficients of output $(Q)$ are about 0.68 , which is comparable to the result of other studies using passenger kilometers as a measure of output. Note also that standard errors are relatively low in both models. This suggests that passenger kilometers is a reasonable measure of output. The coefficients of input prices $\left(P_{C} / P_{L}\right)$ indicate that differences among bus lines can be partially explained by variations in input prices, either capital or labor. Furthermore, the total cost function is concave in input prices at the approximation point. ${ }^{16}$ This

\footnotetext{
${ }^{16}$ For a translog cost function, the concavity condition is satisfied if the Hessian matrix of the second derivatives of total costs with respect to the input prices, $\frac{\partial^{2} \ln C}{\partial \ln P_{j} \partial P_{i}}$, is negatively semidefinite, i.e. if the eigenvalues of the matrix are non-positive. In our analysis with two input
} 
means that management strategies are responsive to changes in input prices. In other words, managers exhibit cost-minimizing behaviour, as predicted by the theory. Since we imposed homogeneity in input prices and symmetry in second-order terms, the estimated total cost frontiers satisfy the conditions for theoretical validity of a total cost frontier model. ${ }^{17}$

Total costs are lower for bus lines with higher average travelling speed $(S)$. This effect is amplified by negative second-order coefficients. The coefficients of the load factor $(L)$ are also negative. Cost elasticity to load factor is much higher than cost elasticity to travelling speed. However, this effect is mitigated by positive second-order coefficients. Combining the coefficients of output and load factor suggests high returns to passenger density. ${ }^{18}$ As predicted, the coefficients of trip length $(T)$ exhibit a negative sign. Conversely, network length $(N)$ has a positive but modest effect on costs. Together with the coefficient of output, this estimated coefficient suggests relatively low returns to scale. The signal-tonoise ratio $(\lambda)$ is about 0.76 and significant in both models, meaning that the standard errors of the cost efficiency terms are slightly larger than those of the noise terms.

In Model $I$, the coefficient of the dummy variable indicating the contractual regime $(d T)$ is positive, but not significant. This suggests that the level of cost efficiency is not influenced by the contractual regime. Our second empirical strategy is based on the results of Model II and the application of the KruskalWallis test, which ranks levels of cost efficiency for the two groups (contractual regimes). The null hypothesis of the test is that there is no statistical difference prices and linear homogeneity imposed, the Hessian matrix reduces to $H=\left(\begin{array}{cc}\beta_{P P} & -\beta_{P P} \\ -\beta_{P P} & \beta_{P P}\end{array}\right)$.

${ }^{17}$ In theory, a valid total cost frontier should be $(i)$ non-negative, $(i i)$ non-decreasing in input prices and output, (iii) linearly homogeneous, and $(i v)$ concave in input prices.

${ }^{18}$ Following Windle (1988), returns to passenger density at the approximation point of a translog cost function are given by the inverse of the sum of both coefficients, i.e. by $\left(\frac{\partial \ln C}{\partial \ln Q}+\frac{\partial \ln C}{\partial \ln L}\right)^{-1}=(0.686-0.502)^{-1}=5.42$ for Model II. Returns to scale are given by $\left(\frac{\partial \ln C}{\partial \ln Q}+\frac{\partial \ln C}{\partial \ln N}\right)^{-1}=(0.686+0.133)^{-1}=1.22$. 
between the two sample groups. The results of the test indicate that we cannot reject the hypothesis of equal distribution of the groups, and are summarized in Table 5. These results confirm those obtained in Model I.

A descriptive summary of the level of cost efficiency obtained from the two models under different contractual regimes is given in Table 4. Cost efficiency scores generated by the two models are highly correlated (see Table 6). The average level of cost efficiency is relatively high. However, the minimum values and the values of the $10^{\text {th }}$ percentile indicate the presence of bus lines characterized by a relatively low level of cost efficiency. In conclusion, differences in the values of cost efficiency among bus lines operating under different contractual regimes are relatively small. Therefore, we can argue that cost efficiency of competitively tendered bus lines is not statistically different from cost efficiency of performance-based negotiated bus lines.

\section{Conclusions}

The revision of the Swiss railways act and its legal ordinances in 1996 induced a fundamental change in the public passenger transportation market. Among other things, regional public authorities were given the choice between two different contractual regimes to procure public passenger transport services: competitive tendering and performance-based negotiation. The more recent revisions of these acts ("Bahnreform II", see Bundesversammlung, 2010) address, among other things, procurement processes of public passenger transportation services. Therefore, information on the effects of different contractual regimes on costs is of relevance for both policy makers and purchasers. Through this study, we investigated levels of cost efficiency of bus lines operated in the Swiss public bus transportation industry under different contractual regimes.

We estimated a translog total cost frontier model using cross-sectional data on 568 bus lines operated by the main bus operator (Postbus) in the year 2009 . 
We applied two different empirical strategies. Through the first strategy, we evaluated differences in the levels of cost efficiency between the contractual regimes using a dummy variable included in the mean of the cost inefficiency. The second strategy is made of two stages. Firstly, a stochastic cost frontier model was estimated. Then, a Kruskal-Wallis equality-of-populations test was applied to assess differences in the ranking of the levels of cost efficiency between the two contractual regimes.

Our empirical results show that the average levels of cost efficiency are relatively high and no significant differences are observed between competitive tendering and performance-based negotiation. Both contractual regimes enforced in Switzerland are incentive regulation schemes. The current practice of using both contractual regimes is challenging for the operators of bus lines in terms of competitive pressure. As stated by Hensher and Wallis (2005), some of the negative effects of negotiation (e.g. high compensation payments) and competitive tendering (e.g. high administrative costs) can be avoided. The possibility of using the competitive tendering may have a disciplining effect on negotiation since it is a credible threat. This threat prevents bus companies from bargaining inadequate rents for bus lines and inducing asymmetric information advantages. This argument is also supported by the recent evidence of cost convergence between competitive tendering and negotiated contracting in Australia (Hensher and Stanley, 2010). 


\section{Acknowledgements}

We are indebted to Souvik Datta (ETH Zurich) for his helpful comments and support. We thank Sumeet Gulati (University of British Columbia) for his critical remarks to an earlier version of this study. Further, we thank Robert Windle (University of Maryland), Silvio Gely and Kaspar Weilenmann (Postbus Switzerland Ltd.) for explanations on load factor and industry background. Access to Swiss Post's data (Postbus Switzerland) is gratefully acknowledged. The responsibility for all errors lies solely with the authors. 


\section{References}

Aigner, Dennis, C. A. Knox Lovell, and Peter Schmidt (1977). Formulation and estimation of stochastic frontier production function models. Journal of Econometrics, 6, $21-37$.

Alexandersson, Gunnar, and Staffan Hultén (2006). Competitive tenders in passenger railway services: Looking into the theory and practice of different approaches in Europe. European Transport, 33, 6-28.

Amaral, Miguel, Stéphane Saussier, and Anne Yvrande-Billon (2009). Auction procedures and competition in public services: The case of urban public transport in France and London. Utilities Policy, 17(2), 166-175.

Amaral, Miguel, Stéphane Saussier, and Anne Yvrande-Billon (2010). Does competition for the field improve cost efficiency? Evidence from the London bus tendering model. IAE - Pantheon-Sorbonne, 1-25.

Armstrong, Mark, and David E. M. Sappington (2006). Regulation, Competition, and Liberalization. Journal of Economic Literature, 44, 325-366.

Armstrong, Mark, and David E. M. Sappington (2007). Recent developments in the theory of regulation, in Handbook of Industrial Organization, Mark Armstrong and Robert Porter, (eds.). Elsevier, 1557-1700.

Augustin, Katrin, and Matthias Walter (2010). Operator changes through competitive tendering: Empirical evidence from German local bus transport. Research in Tranportation Economics, 29(1), 36-44.

Baird, Alfred J., and Gordon Wilmsmeier (2011). Public tendering of ferry services in Europe. European Transport, 49, 90-111.

Battese, George E., and Tim Coelli (1995). A model for technical inefficiency effects in a stochastic frontier production function for panel data. Empirical Economics, 20, $325-332$.

BAV (2003). Leitfaden zur Ausschreibung von Personentransportleistungen im öffentlichen Verkehr (Busbereich). Eidgenössisches Departement für Umwelt, Verkehr, 
Energie und Kommunikation (UVEK), Bundesamt für Verkehr (BAV).

Bekken, Jon-Terje, Frode Longva, Nils Fearnley, and Oddgeir Osland (2006). Norwegian experiences with tendered buss services. European Transport, 33, 29-40.

Berechman, Joseph (1987). Cost structure and production technology in transit: An application to the Israeli bus transit sector. Regional Science and Urban Economics, 17(4), 519-534.

Bhattacharyya, Arunava, Subal C. Kumbhakar, and Anjana Bhattacharyya (1995). Ownership structure and cost efficiency: A study of publicly owned passenger-bus transportation companies in India. Journal of Productivity Analysis, 6(1), 47-61.

Boitani, Andrea, Marcella Nicolini, and Carlo Scarpa (2013). Do competition and ownership matter? Evidence from local public transport in Europe. Applied Economics, 45(10-12), 1419-1434.

Bundesversammlung (2010). 05.028 - Botschaft zum zweiten Schritt der Bahnreform II, Curia Vista Geschäftsdatenbank. http://www.parlament.ch/d/suche/seiten/geschaefte.aspx?gesch_id=20050028.

Cambini, Carlo, Massimo Filippini, Massimiliano Piacenza, and Davide Vannoni (2011). Corporatization and firm performance: evidence from publicly-provided local utilities. Review of Law and Economics, 7(1), 191-213.

Christensen, Laurits R., Dale W. Jorgenson, and Lawrence J. Lau (1973). Transcendental Logarithmic Production Frontier. Review of Economics and Statistics, 55, 28-45. Cook, R. Dennis (1977). Detection of influential observation in linear regression. Technometrics, 19(1), 15-18.

Cullmann, Astrid, Mehdi Farsi, and Massimo Filippini (2012). Unobserved heterogeneity and efficiency measurement in public transport. Journal of Transport Economics and Policy, 46(1), 51-66.

Dalen, Dag M., and Andres Goméz-Lobo (2003). Yardsticks on the road: Regulatory contracts and cost efficiency in the Norwegian bus industry. Transportation, 30, 371386. 
De Borger, Bruno, and Kristiaan Kerstens (2008). The performance of bus-transit operators, in Handbook of Transport Modelling, David A. Hensher and Kenneth J. Button, (eds.). Elsevier, 577-596.

Deb, Kaushik, and Massimo Filippini (2011). Estimating welfare changes from efficient pricing in public bus transit in India. Transport Policy, 18(1), 23-31.

Demsetz, Harold (1968). Why regulate utilities? Journal of Law and Economics, 11(1), $55-65$.

EBG (1957). Eisenbahngesetz, SR 742.101. http://www.admin.ch/opc/de/classifiedcompilation/19570252/index.html.

Farsi, Mehdi, Massimo Filippini, and Michael Kuenzle (2006). Cost efficiency in regional bus companies. Journal of Transport Economics and Policy, 40(1), 95-118.

Filippini, Massimo, and Paola Prioni (1994). Is scale and cost inefficiency in the Swiss bus industry a regulatory problem? Evidence from a frontier cost approach. International Journal of the Economics of Business, 1(2), 219-232.

Filippini, Massimo, and Paola Prioni (2003). The influence of ownership on the cost of bus service provision in Switzerland - an empirical illustration. Applied Economics, 35(6), 683-690.

Fraquelli, Giovanni, Massimiliano Piacenza, and Graziano Abrate (2004). Regulating public transit networks: How do urban-intercity diversification and speed-up measures affect firms' cost performance? Annals of Public and Cooperative Economics, 75(2), $193-225$.

Friedlaender, Ann F., and Judy S.-E. Wang Chiang (1983). Productivity growth in the regulated trucking industry. Research in Transportation Economics, 1, 149-184.

Gagnepain, Philippe (1998). Structures productives de l'industrie du transport urbain et effets des schémas réglementaires. Économie et prévision, 135(4), 95-107.

Gil, Richard, and Justin Marion (2012). Self-enforcing agreements and relational contracting: evidence from California highway procurement. Journal of Law, Economics, and Organization, doi: 10.1093/jleo/ewr026. 
Hensher, David A. (1988). Some thoughts on competitive tendering in local bus operations. Transport Reviews, 8(4), 363-372.

Hensher, David A., and John Stanley (2008). Transacting under a performance-based contract: The role of negotiation and competitive tendering. Transportation Research Part A, 42, 1143-1151.

Hensher, David A., and John Stanley (2010). Contracting regimes for bus services: What have we learnt after 20 years? Research in Transportation Economics, 29(1), $140-144$.

Hensher, David A., and Ian P. Wallis (2005). Competitive tendering as a contracting mechanism for subsiding transport. Journal of Transport Economics and Policy, 39(3), 295-321.

Jara-Díaz, Sergio R., Cristián Cortés, and Freddy Ponce (2001). Number of points served and economies of spatial scope in transport cost functions. Journal of Transport Economics and Policy, 35(2), 327-341.

Jehle, Geoffrey A., and Philip J. Reny (2001). Advanced Microeconomic Theory: Addison Wesley.

Jha, Raghbendra, and Sanjay K. Singh (2001). Small is efficient: A frontier approach to cost inefficiencies in Indian state road transport undertakings. International Journal of Transport Economics, 28(1), 95-114.

Jondrow, James, C. A. Knox Lovell, Ivan S. Materov, and Peter Schmidt (1982). On the estimation of technical inefficiency in the stochastic frontier production function model. Journal of Econometrics, 19(2-3), 233-238.

Kruskal, William H., and W. Allen Wallis (1952). Use of ranks in one-criterion variance analysis. Journal of the American Statistical Association, 47(260), 583-621.

LITRA - Informationsdienst für den öffentlichen Verkehr (2014). Verkehrzahlen, Ausgabe 2014 .

Mathisen, Terje Andreas, and Gisle Solvoll (2008). Competitive tendering and structural changes: An example from the bus industry. Transport Policy, 15(1), 1-11. 
Merkert, Rico (2010). Changes in transaction costs over time - The case of franchised train operating firms in Britain. Research in Transportation Economics, 29(1), 52-59. Mizutani, Fumatoshi, and Takuya Urakami (2003). A private-public comparison of bus service operators. International Journal of Transport Economics, 30, 167-185.

Mohring, Herbert (1972). Optimization and scale economies in urban bus transportation. The American Economic Review, 62(4), 591-604.

Mouwen, Arnoud, and Piet Rietveld (2013). Does competitive tendering improve customer satisfaction with public transport? A case study for the Netherlands. Transportation Research Part A, 51, 29-45.

Nash, Chris, and Michał Wolański (2010). Workshop report - Benchmarking the outcome of competitive tendering. Research in Transportation Economics, 29, 6-10.

Nieswand, Maria, and Matthias Walter (2010). Cost efficiency and subsidization in German local public bus transit. DIW Berlin.

Ottoz, Elisabetta, Graziella Fornengo, and Marina Di Giacomo (2009). The impact of ownership on the cost of bus service provision: an example from Italy. Applied Economics, 41(3), 337-349.

Pestana Barros, Carlos, and Nicolas Peypoch (2010). Productivity changes in Portuguese bus companies. Transport Policy, 17(5), 295-302.

Piacenza, Massimiliano (2006). Regulatory contracts and cost efficiency: Stochastic frontier evidence from the Italian local public transport. Journal of Productivity Analysis, 25(3), 257-277.

Preston, John M. (2005). Tendering of services. In Handbook of Transport Strategy, Policy and Institutions. Kenneth J. Button and David A. Hensher, (eds.). Elsevier Science, 65-82.

Roy, William, and Anne Yvrande-Billon (2007). Ownership, contractual practices and technical efficiency: The case of urban public transport in France. Journal of Transport Economics and Policy, 41(2), 257-282.

Sakai, Hiroki, and Kenichi Shoji (2010). The effect of governmental subsidies and the 
contractual model on the publicly-owned bus sector in Japan. Research in Transportation Economics, 29(1), 60-71.

Saussier, Stéphane, Carine Staropoli, and Anne Yvrande-Billon (2009). Public-private agreements, institutions, and competition: When economic theory meets facts. Review of Industrial Organization, 35(1), 1-18.

Shleifer, Andrei (1985). A theory of yardstick competition. Rand Journal of Economics, 16(3), 319-327.

Singh, Satbir, and Tim Coelli (2001). Performance of dairy plants in the cooperative and private sectors in India. Annals of Public and Cooperative Economics, 72 (4), $453-479$.

Smith, Andrew S. J., Phill E. Wheat, and Chris A. Nash (2010). Exploring the effects of passenger rail franchising in Britain: Evidence from the first two rounds of franchising (1997-2008). Research in Transportation Economics, 29(1), 72-79.

Stanley, John, and Didier van de Velde (2008). Risk and reward in public transport contracting. Research in Transportation Economics, 22(1), 20-25.

Tadelis, Steven, and Patrick Bajari (2006). Incentives and award procedures: competitive tendering vs. negotiations in procurement. In Handbook of Procurement. Dimitri, Piga, and Spagnolo (Eds.), Cambridge University Press

Wallis, Ian, David Bray, and Heather Webster (2010). To competitively tender or to negotiate - Weighing up the choices in a mature market. Research in Transportation Economics, 29(1), 89-98.

Walter, Matthias (2010). Efficiency and comptition in public transport, University of Technology, Dresden.

Walter, Matthias (2011). Some determinants of cost efficiency in German public transport. Journal of Transport Economices and Policy, 45(1), 1-20.

Wang Chiang, Judy S.-E., and Ya-Wen Chen (2005). Cost structure and technological change of local public transport: the Kaohsiung City Bus case. Applied Economics, 37(12), 1399-1410. 
Weidmann, U., Spacek, P., Dorbritz, R., Puffe, E., Santel, G., 2011. Bedeutung des öffentlichen Strassenverkehrs in der Schweiz. Grundlagenstudie. Institute for Transport Planning and Systems, ETH Zurich, March 2011.

Windle, Robert J (1988). Transit policy and the cost structure of urban bus transportation, in Bus deregulation and privatization: An international perspective, John S Dodgson and Neville Topham, (eds.). Gower, 119-140.

Yescombe, Edward R. (2007). Public private partnerships: Principles of policy and finance, Amsterdam: Elsevier.

Yvrande-Billon, Anne (2006). The attribution process of delegation contracts in the French urban public transport sector: Why competitive tendering is a myth. Annals of Public and Cooperative Economics, 77(4), 453-478. 


\begin{tabular}{lcc}
\hline Variables & Mean & Std. Dev. \\
\hline Total costs $(C)$ in Swiss francs & 725,187 & 769,468 \\
Passenger kilometers $(Q)$ & $1,093,431$ & $1,926,202$ \\
Price of labour $\left(P_{L}\right)$ in Swiss francs & 51.53 & 5.35 \\
Price of capital $\left(P_{C}\right)$ in Swiss francs & 3.22 & 1.04 \\
Average travelling speed $(S)$ in km/h & 21.08 & 6.88 \\
Load factor $(L)$ in passenger km per seat km* & 1 & 0.6 \\
Average trip length $(T)$ in km & 6.13 & 3.38 \\
Network length $(N)$ in km & 12.38 & 8.88 \\
Competitive tendering $(d T=1,0$ otherwise $)$ & 0.08 & 0.27 \\
\hline
\end{tabular}

Notes: number of observations $\mathrm{n}=568 ;{ }^{*}$ normalized values $($ mean $=1)$.

Table 1: Descriptive statistics of total costs, output and input variables.

\begin{tabular}{lcc}
\hline & Model I & Model II \\
& SFA + dummy $f\left(\mu_{i}\right)$ & SFA \\
\hline$d T$ & Function of the mean inefficiency & Not included \\
Composite error $\left(\varepsilon_{i}\right)$ & $\varepsilon_{i}=\mu_{i}+\nu_{i}$ & $\varepsilon_{i}=\mu_{i}+\nu_{i}$ \\
& $\mu_{i} \sim N^{+}\left(\beta_{d T} d T, \sigma_{\mu}^{2}\right)$ & $\mu_{i} \sim N^{+}\left(0, \sigma_{\mu}^{2}\right)$ \\
Inefficiency & $\nu_{i} \sim N\left(0, \sigma_{\nu}^{2}\right)$ & $\nu_{i} \sim N\left(0, \sigma_{\nu}^{2}\right)$ \\
Level of efficiency & $E\left[\mu_{i} \mid \varepsilon_{i}\right]$ & $E\left[\mu_{i} \mid \varepsilon_{i}\right]$ \\
Kruskal-Wallis test & $\exp \left(-E\left[\mu_{i} \mid \varepsilon_{i}\right]\right)$ & $\exp \left(-E\left[\mu_{i} \mid \varepsilon_{i}\right]\right)$ \\
\hline
\end{tabular}

Table 2: Econometric specifications. 


\begin{tabular}{|c|c|c|c|c|}
\hline & \multicolumn{2}{|c|}{$\begin{array}{c}\text { Model I } \\
\text { SFA }+ \text { dummy } f\left(\mu_{i}\right)\end{array}$} & \multicolumn{2}{|c|}{$\begin{array}{c}\text { Model II } \\
\text { SFA }\end{array}$} \\
\hline & Coefficients & Std. Err. & Coefficients & Std. Err. \\
\hline Passenger kilometers $(Q)$ & $0.6862^{* * *}$ & 0.016 & $0.6864^{* * *}$ & 0.014 \\
\hline Input price ratio $(P)$ & $0.7932^{* * *}$ & 0.058 & $0.7931^{* * *}$ & 0.045 \\
\hline Average travelling speed $(S)$ & $-0.3432^{* * *}$ & 0.058 & $-0.3437^{* * *}$ & 0.049 \\
\hline Load factor $(L)$ & $-0.5015^{* * *}$ & 0.040 & $-0.5020^{* * *}$ & 0.038 \\
\hline Average trip length $(T)$ & $-0.1278^{* * *}$ & 0.046 & $-0.1291^{* * *}$ & 0.037 \\
\hline Network length $(N)$ & $0.1323^{* * *}$ & 0.039 & $0.1330^{* * *}$ & 0.029 \\
\hline$(Q Q)$ & $0.1256^{* * *}$ & 0.018 & $0.1251^{* * *}$ & 0.016 \\
\hline$(P P)$ & $-0.1350^{* *}$ & 0.064 & $-0.1327^{* * *}$ & 0.048 \\
\hline$(S S)$ & $-0.3492^{*}$ & 0.204 & $-0.3450^{*}$ & 0.205 \\
\hline$(L L)$ & $0.2936^{* * *}$ & 0.049 & $0.2920^{* * *}$ & 0.049 \\
\hline$(T T)$ & -0.1599 & 0.145 & -0.1513 & 0.137 \\
\hline$(N N)$ & -0.0396 & 0.094 & -0.0347 & 0.084 \\
\hline$(Q P)$ & $-0.0929^{* *}$ & 0.040 & $-0.0955^{* * *}$ & 0.032 \\
\hline$(Q S)$ & -0.0081 & 0.050 & -0.0059 & 0.039 \\
\hline$(Q L)$ & $-0.1649^{* * *}$ & 0.031 & $-0.1644^{* * *}$ & 0.028 \\
\hline$(Q T)$ & -0.0309 & 0.039 & -0.0314 & 0.033 \\
\hline$(Q N)$ & 0.0299 & 0.041 & 0.0299 & 0.029 \\
\hline$(P S)$ & $0.5663^{* * *}$ & 0.153 & $0.5621^{* * *}$ & 0.148 \\
\hline$(P L)$ & $0.1813^{* * *}$ & 0.053 & $0.1834^{* * *}$ & 0.059 \\
\hline$(P T)$ & -0.0919 & 0.102 & -0.0889 & 0.112 \\
\hline$(P N)$ & 0.0835 & 0.075 & 0.0868 & 0.063 \\
\hline$(S L)$ & 0.1013 & 0.064 & 0.1001 & 0.068 \\
\hline$(S T)$ & 0.0012 & 0.094 & 0.0000 & 0.114 \\
\hline$(S N)$ & $-0.2019^{* *}$ & 0.087 & $-0.2096^{* *}$ & 0.096 \\
\hline$(L T)$ & 0.0663 & 0.061 & 0.0649 & 0.063 \\
\hline$(L N)$ & -0.0141 & 0.057 & -0.0150 & 0.060 \\
\hline$(T N)$ & 0.1005 & 0.076 & 0.0984 & 0.077 \\
\hline$d T$ as $f\left(\mu_{i}\right)$ & 0.0433 & 0.110 & & \\
\hline Constant & $11.7335^{* * *}$ & 0.051 & $11.7340^{* * *}$ & 0.060 \\
\hline$\sigma^{2}=\sigma_{\mu}^{2}+\sigma_{\nu}^{2}$ & $0.0683^{* * *}$ & 0.012 & $0.0687^{* * *}$ & 0.015 \\
\hline$\lambda=\sigma_{\mu}^{2} / \sigma_{\nu}^{2}$ & $0.7632^{* * *}$ & 0.342 & $0.7672^{* * *}$ & 0.089 \\
\hline
\end{tabular}

Table 3: Estimation results. 


\begin{tabular}{lcccc}
\hline & \multicolumn{2}{c}{ Model I } & \multicolumn{2}{c}{$\begin{array}{c}\text { Model II } \\
\text { SFA }\end{array}$} \\
\hline Contractual regime & $\begin{array}{c}\text { Performance-based } \\
\text { negotiation }\end{array}$ & $\begin{array}{c}\text { Competitive } \\
\text { tendering }\end{array}$ & $\begin{array}{c}\text { Performance-based } \\
\text { negotiation }\end{array}$ & $\begin{array}{c}\text { Competitive } \\
\text { tendering }\end{array}$ \\
\hline Mean & 0.8822 & 0.8757 & 0.8818 & 0.8791 \\
Standard deviation & 0.0360 & 0.0401 & 0.0363 & 0.0367 \\
Minimum & 0.6356 & 0.7652 & 0.6321 & 0.7756 \\
$10^{\text {th }}$ percentile & 0.8401 & 0.8347 & 0.8394 & 0.8419 \\
$1^{\text {st }}$ quantile & 0.8694 & 0.8568 & 0.8688 & 0.8618 \\
Median & 0.8886 & 0.8778 & 0.8881 & 0.8828 \\
$3^{\text {rd }}$ quantile & 0.9040 & 0.8976 & 0.9036 & 0.8989 \\
90 & 0.9171 & 0.9292 & 0.9168 & 0.9279 \\
Maximum & 0.9653 & 0.9470 & 0.9652 & 0.9432 \\
\hline Number of observations: $\mathrm{n}=568$. & & & &
\end{tabular}

Table 4: Cost efficiency scores.

\begin{tabular}{lcc}
\hline & $\begin{array}{c}\text { Model II } \\
\text { SFA }\end{array}$ \\
\hline Contractual regime & Performance-based negotiation & Competitive tendering \\
\hline Average rank & 282 & 305 \\
$H_{0}:$ eff $(\mathrm{dT}=0)$ & \multicolumn{2}{c}{ not rejected } \\
$P$-value & \multicolumn{2}{c}{0.349} \\
\hline Lower efficiency values are assigned to higher ranks; ${ }^{* * *},{ }^{* *},{ }^{*}:$ & significant at $1 \%, 5 \%$ and $10 \%$,
\end{tabular}
respectively; number of observations: $\mathrm{n}=568$.

Table 5: Kruskal-Wallis equality-of-population test (cost efficiency scores).

\begin{tabular}{lcc}
\hline & Model I & Model II \\
& SFA + dummy $f\left(\mu_{i}\right)$ & SFA \\
\hline Model I & 1 & $0.9994^{* * *}$ \\
Model II & $0.9992^{* * *}$ & 1 \\
\hline
\end{tabular}

Note: correlation of efficiency scores in the lower triangle matrix, Spearman rank correlation in the upper triangle matrix; ***, **, *: significant at $1 \%, 5 \%$ and $10 \%$, respectively; number of observations: $\mathrm{n}=568$.

Table 6: Correlation of cost efficiency scores (upper triangle matrix) and Spearman rank correlation (lower triangle matrix). 


\section{IdEP Economic Papers}

The series IdEP Economic Papers, ideally continues the work of the "Quaderni della Facoltà" the publication of which began in 1998 and ended in 2013.

For a complete list of the Quaderni see: http://econpapers.repec.org/paper/lugwpaper/

IdEP Economic Papers also gathers the legacy of the CEPRA Working Papers, published from 2012 to 2013.

The full list at: http://econpapers.repec.org/paper/lugwcepra/

\section{4:}

No. 01

F. Mazzonna, F. Peracchi, Unhealthy retirement? Evidence of occupation heterogeneity

No. 02

L. Di Giorgio, M. Filippini, G. Masiero, The relationship between costs and quality in nonprofit nursing homes

No. 03

F.C. Billari, V. Galasso, Fertility decisions and pension reforms : evidence from natural experiments in Italy

No. 04

M. Jametti, M. Joanis, Elections and de facto expenditure decentralization in Canada

No. 05

M. Jametti, Weathering the global financial crisis : is direct democracy of any help?

No. 06

U. Pagano, M. Vatiero, Costly institutions as substitutes : novelty and limits of the Coasian approach

No. 07

R. Parchet, Are local tax rates strategic complements or strategic substitutes?

No. 08

R. Ippoliti, M. Vatiero, An analysis of how 2002 judicial reorganization has impacted on the performance of the First Instance Courts (Preture) in Ticino

No. 09

F. Mazzonna, P. Salari, Short term effects of public smoking bans on health 
2015:

No. 01

S. Galletta, Direct democracy, partial decentralization and voter information : evidence from Swiss municipalities

No. 02

I. Sarman, Second homeowners' intention to move : an integrated ordered logit model with latent variable

No. 03

M.J. Roe, M. Vatiero, Corporate governance and its political economy

No. 04

M. Filippini, M. Koller, G. Masiero, Competitive tendering versus performance-based negotiation in Swiss public transport 